\title{
Airborne LiDAR Measurements of Sea Surface Properties in the German Bight
}

\author{
Konrad Bärfuss $^{\circledR}$, Bughsin Djath ${ }^{\circledR}$, Astrid Lampert ${ }^{\circledR}$, and Johannes Schulz-Stellenfleth ${ }^{\circledR}$
}

\begin{abstract}
Sea surface measurements are mainly gathered using satellite altimeter, buoy, and platform measurements. Satellite measurements typically have a coarse spatial resolution and need recalibration in coastal regions, whereas point measurements of buoys only represent limited areas around the measurement point because of the complex coastal bathymetry. Wave models (WAM) are used to expand the sparse observations in space and time. As a part of the project WIndPArk far-field (WIPAFF), which focused on wakes behind offshore wind farms, extensive airborne light detection and ranging (LiDAR) measurements of ocean waves in the German Bight were performed for more than $90 \mathrm{~h}$. The LiDAR data processed for significant wave height can be used to validate and improve WAM models for complex areas and fill the observation gap between satellite altimeter and point measurements. This creates a detailed picture of the sea surface for coastal engineering and environmental applications. After introducing the measurement techniques and the data situation, intercomparisons between the available airborne measurements, buoy data, and WAM model output are presented to provide an insight into the potential of airborne LiDAR measurements for wave characterization and wave model validation.
\end{abstract}

Index Terms-Oceanographic techniques, sea coast, sea measurements, sea surface, waves.

\section{INTRODUCTION}

$\mathbf{I}$ NFORMATION on ocean waves is of crucial importance for many practical applications, e.g., coastal engineering and geoscience, in particular in coastal areas with a lot of shipping and offshore activities (some examples are given in [1]). Furthermore, information about ocean waves is required for atmosphere/ocean coupling mechanisms [2] or sediment transport processes [3]. Therefore, information about ocean waves has been of increasing interest within the research community over the last years.

However, sea surface properties in coastal areas are generally complex to describe analytically and in models because

Manuscript received November 25, 2019; revised July 19, 2020; accepted August 16, 2020. This work was supported by the German Federal Ministry for Economic Affairs and Energy through the Project WIPAFF for Airborne Observations under Grant 0325783B. (Corresponding author: Konrad Bärfuss.)

Konrad Bärfuss and Astrid Lampert are with the Work Group of Airborne Meteorology and Measurement Techniques, Institute of Flight Guidance, Technische Universitat Carolo-Wilhelmina zu Braunschweig, 38108 Braunschweig, Germany (e-mail: k.baerfuss@tu-braunschweig.de).

Bughsin Djath and Johannes Schulz-Stellenfleth are with the Institute of Coastal Research, Helmholtz-Zentrum Geesthacht, 21502 Geesthacht, Germany.

Color versions of one or more of the figures in this article are available online at http://ieeexplore.ieee.org.

Digital Object Identifier 10.1109/TGRS.2020.3017861 of the erratic bathymetry, the fast-changing, and local fetch and dissipation processes [4].

Particularly, in coastal areas, such as the German Bight with lumpy and shallow bathymetry, there is still room for improvement regarding the physical parameterizations or the definition of boundary conditions and forcing fields [5]. In this area, the situation is complicated by the fact that the ocean wavelength is often longer than the water depth. Consequently, the equations that are normally used for dissipation have to be refined.

Traditionally, ocean waves are treated in the spectral domain (see [6]-[9]), and respective numerical ocean wave forecast models have been developed, which have reached a reasonable level of accuracy compared with buoys with a root mean square (rms) around $0.2 \mathrm{~m} \mathrm{[10].} \mathrm{However,} \mathrm{certain} \mathrm{processes,}$ such as bed friction, wave breaking, or wave generation, are not parameterized with a qualitative relationship to the observed features [11]. Therefore, measurements are necessary to identify improvement potential in models, wave parameterizations, and model boundary conditions.

Today, mainly two kinds of data sets for ocean waves are available to the community: point measurements recorded on buoys or platforms, and satellite altimeter measurements. Point measurements only represent their close surroundings depending on bathymetry and forcing conditions (e.g., the Forschungsplattform in Nord- und Ostsee (FINO) 1 and 3 offshore measurement platforms in the German Bight [12]), whereas satellite altimeter data have a coarse spatial resolution with a footprint size of typically about $5 \mathrm{~km}$ depending on the system. The data are often deteriorated near the coastline due to land effects on backscatter. In between point and satellite altimeter measurements, there is an observation gap for area-covering measurements with small-scale resolution.

During the project WIndPArk far-field (WIPAFF), [13], [14], airborne measurements were performed in the German Bight with the aim to characterize the modified flow field downwind of offshore wind parks. One key objective was to improve the knowledge of the sea surface roughness, which is an important factor for wind profiles and turbulence (see [15]). Therefore, a laser scanner to measure the 3-D sea surface elevation similar to the measurements in [16]-[19] was integrated on board of the research aircraft Dornier 128 D-IBUF of TU Braunschweig (Germany) [20], [21]. The data are well suited to study gradients in wave energy either 
TABLE I

Airborne Laser Scanner Measurement Parameters

\begin{tabular}{lr}
\hline \hline Parameter & Value \\
\hline Effective measurement rate & $30-122 \mathrm{kHz}$ \\
Laser wavelength & $1550 \mathrm{~nm}$ \\
Laser power & $4500 \mu \mathrm{W}$ \\
Accuracy and precision along beam direction & $<10 \mathrm{~mm}$ \\
Resulting scan pattern & line scan \\
Typical operational carrier velocity & $\approx 65 \mathrm{~m} \mathrm{~s}^{-1}$ \\
Typical operational altitude AMSL & $100 \mathrm{~m}$ \\
Typical operational footprint diameter & $30 \mathrm{~cm}$ \\
Typical operational point spacing lateral and longitudinal & $\approx 0.5 \mathrm{~m}$ \\
\hline \hline
\end{tabular}

associated with wave generation or wave dissipation. Wave propagation is strongly influenced by the bathymetry in these conditions with complex nonlinear coupling and dissipation effects [5].

For most applications, sea surface is described using the parameter significant wave height (SWH). In forcing conditions (wind sea) with overlaying waves originated far from the measurement area (swell), sea surface is best described by directional spectra. Nevertheless, a description of surface properties with SWH and main wave direction is sufficient for many applications.

After introducing the technique of LiDAR measurements of the sea surface and presenting the available data set, the airborne remote sensing data will be validated against in situ measurements. A case study then shows the potential of LiDAR data to complement buoy, platform, and satellite measurements in a synoptic condition with wind from the coast and, therefore, complicated fetch conditions for wave generation caused by the coastline and small islands.

\section{LIDAR SYSTEM}

The system used for sea surface measurements consists of a laser scanner integrated in the research aircraft D-IBUF [20], [21], which is further equipped with multiple navigation and attitude sensors, as well as meteorological sensors [20]. As the scanning LiDAR of type RIEGL VZ-1000 (RIEGL Laser Measurement Systems GmbH, Austria) is usually used for ground-based 3-D terrestrial scanning, its integration had to consider moderate shocks and vibrations. Table I gives an overview of the instrument and measurement parameters.

Although reflectance is low for nonperpendicular incident angles on the water surfaces at the instrument wavelength of $1550 \mathrm{~nm}$, experiments showed sufficient returns for surface analysis over the North Sea. The effective return rate was around 4000 point measurements/s.

To integrate the laser scanner into the research aircraft, a special mount was constructed. Protection against aircraft accelerations and vibrations was accomplished by adding another hinge to the turning head mechanism inside a frame.
This frame is attached through shock mounts to a ground plate fastened onto the seat rails around a floor hatch in the fuselage.

The system is capable of measuring water surface elevation in a line scan pattern with a point spacing of approximately $0.5 \mathrm{~m}$ in the lateral and longitudinal directions. Since reflectance decreases with increasing impact angles compared with sea surface normals, a strip width of 50-100 m can be scanned, depending on the altitude above sea level, surface properties, and measurement settings of the LiDAR instrument. Since accurate position and attitude measurements are needed for geolocating distance measurements, the inertial navigation system (INS) iMAR RQH (iMAR Navigation $\mathrm{GmbH}$, Germany) is used in the research aircraft Do- 128 .

\section{A. Data Set Overview}

During the measurement campaigns of the project WIPAFF, more than $90 \mathrm{~h}$ of LiDAR data were collected between September 6, 2016, and August 17, 2017, in 39 flights during different weather and sea state conditions. The flight patterns were arranged perpendicular to the wind direction crossing the wake of the wind park on flight legs of $45-\mathrm{km}$ length, at various distances with a separation of $10-\mathrm{km}$ downwind of the wind park. Wake measurements were performed at an altitude of 90-120 m above sea level, depending on wind turbine hub height of the upstream wind park generating the wake. A graphical overview of the data set is shown in Fig. 1.

\section{B. Significant Wave Height Estimation}

Raw surface measurements are referenced in the scanner's coordinate system. These measurements have to be transformed by Eulerian angles and displaced by the carrier position and a lever arm correction. This produces georeferenced measurement points, which can be used for subsequent calculations. An example of a georeferenced point cloud of the sea surface at position at $6.8^{\circ} \mathrm{E}, 54.2^{\circ} \mathrm{N}$ on May 31,2017 , at 10:17 UTC is shown in Fig. 2.

For calculating the significant wave height $H_{s}$, the approximation $H_{s}=4 \cdot \operatorname{std}(\eta)$ (four times the standard deviation of the surface elevations $\eta$ [4]) is chosen as the most simple estimate for SWH considering the wave height Rayleigh distributed. Although scale factors were approximated in the literature to connect the classical significant wave height (the average height of the highest one-third of all waves) $H_{1 / 3}$ and $H_{m 0}$ (four times the square root of the zeroth-order moment of the wave spectrum), for example, $H_{1 / 3}=0.927 \cdot H_{m_{0}}$ [22] for the North Sea, these differences in the range of $5 \%-10 \%$ are not further considered here.

To approximate $\mathrm{SWH}$, the georeferenced point cloud is split in parts of $10 \mathrm{~s}$ to maintain the balance of statistical base with an average of $N=30000$ measurement points, and the spatial resolution corresponds to $0.5 \mathrm{~km}$. Since absolute height is a critical parameter for INS, all measurements of the surface height were linearly detrended over time inside the corresponding 10-s windows. This results in a point cloud with a size of approximately $500 \mathrm{~m} \times 65 \mathrm{~m}$ for the estimation of significant wave height using $H_{s}=4\left(\left\langle\eta^{2}\right\rangle\right)^{1 / 2}$, where $\left\langle\eta^{2}\right\rangle$ is the variance of the sea surface elevations 


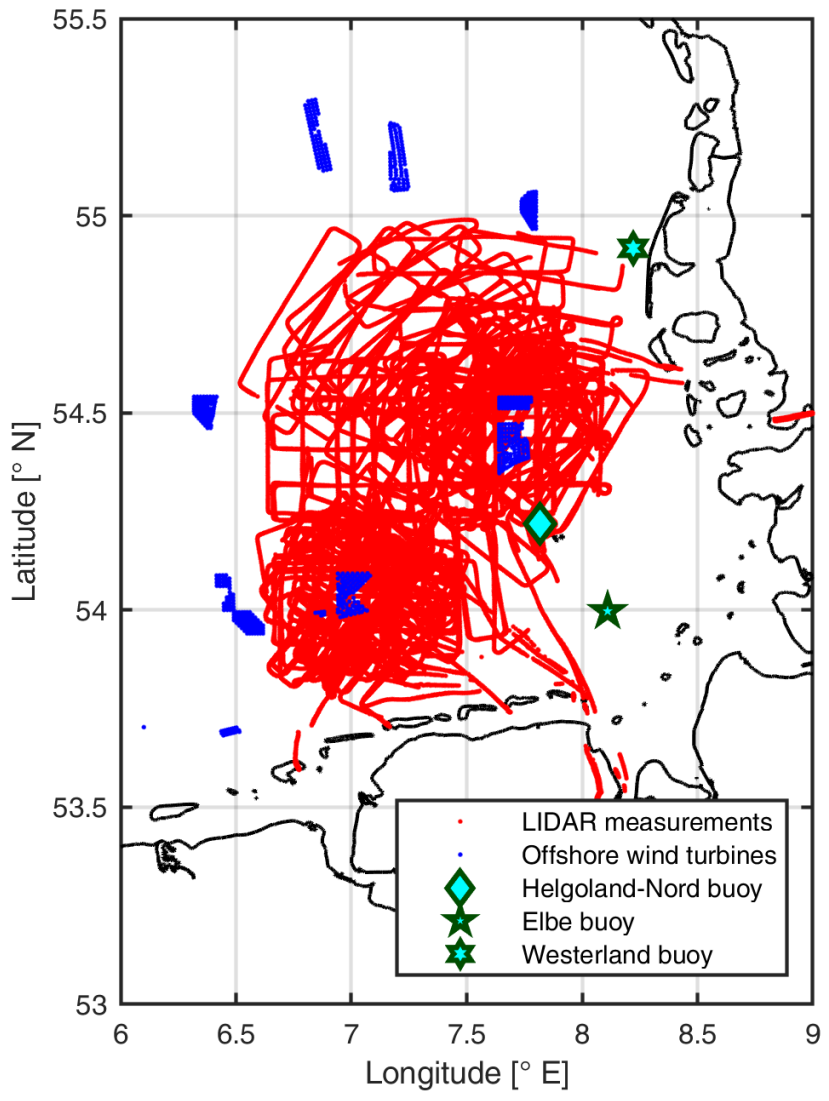

Fig. 1. Overview of LiDAR measurements taken in the German Bight between September 6, 2016, and August 17, 2017, during 39 flights. Red are downsampled data returns of the LiDAR (downsampled by factor 5000). The flight patterns were performed mainly downwind of wind parks; therefore, every single operational wind turbine in April 2017 is indicated in blue. The diamond, pentagram, and hexagram marks indicate the positions of the wave buoys "Helgoland-Nord," "Elbe," and "Westerland."

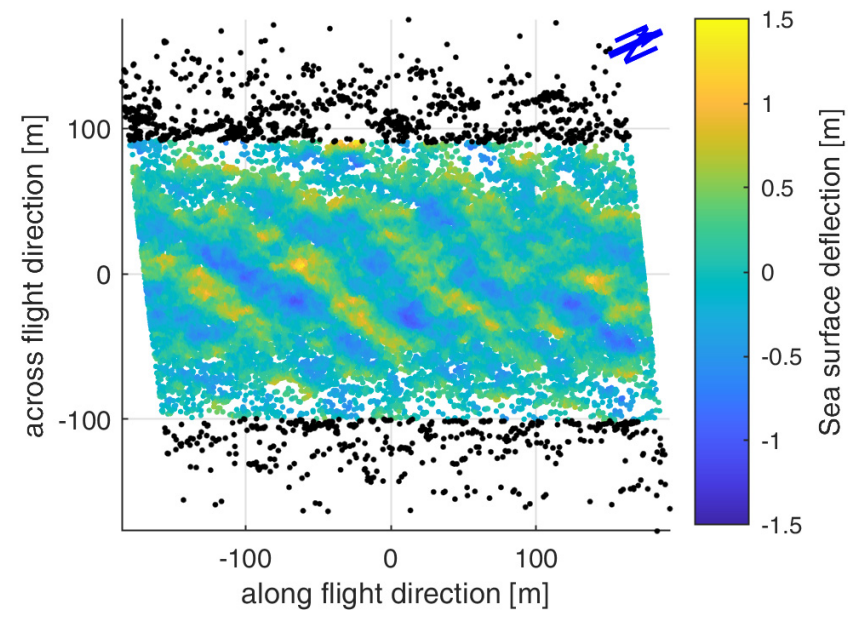

Fig. 2. Example of surface measurements during a time span of $5 \mathrm{~s}$ at $6.8^{\circ} \mathrm{E}$, $54.2^{\circ} \mathrm{N}$ on May 31,2017 , at 10:17 UTC. The sea surface deflection from the mean surface level is color-coded. The flight direction is from the right to the left, the blue arrow points to the North direction.

$\eta$. This method provides stable estimations of $\mathrm{H}_{s}$. In the example of georeferenced sea surface deflection measurements in Fig. 2, the resulting $H_{S}$ for the surface example shown is $H_{s}=1.4 \mathrm{~m}$.
As the motion of the sea surface must be regarded as a stochastic process, errors have to be discussed using sea surface spectra. The $H_{S}$ measurements discussed in this study are based on the standard variance estimator

$$
\zeta=: \operatorname{var}(\eta)=\frac{1}{N} \sum_{i=1}^{N} \eta_{i}^{2}
$$

where $\eta_{i}, i=1, \ldots, N$, are the individual elevation measurements, using the fact that mean $(\eta)=0$ according to the definition of water elevation.

The uncertainty of $\zeta$ can be written as

$$
\operatorname{var}(\zeta)=\frac{1}{N^{2}} \sum_{i, j=1}^{N}\left\langle\eta_{i}^{2} \eta_{j}^{2}\right\rangle-\frac{1}{N^{2}} \sum_{i, j=1}^{N}\left\langle\eta_{i}^{2}\right\rangle\left\langle\eta_{j}^{2}\right\rangle .
$$

For a Gaussian distribution, the first term can be rewritten as (see [23])

$$
\begin{aligned}
\operatorname{var}(\zeta) \approx & \frac{1}{N^{2}} \sum_{i, j=1}^{N}\left(\left\langle\eta_{i}^{2}\right\rangle\left\langle\eta_{j}^{2}\right\rangle+2\left\langle\eta_{i}, \eta_{j}\right\rangle^{2}\right) \\
& -\frac{1}{N^{2}} \sum_{i, j=1}^{N}\left\langle\eta_{i}^{2}\right\rangle\left\langle\eta_{j}^{2}\right\rangle \\
= & \frac{2}{N^{2}} \sum_{i, j=1}^{N}\left\langle\eta_{i}, \eta_{j}\right\rangle^{2} \\
= & \frac{H_{S}{ }^{4}}{128 N}+\frac{4}{N^{2}} \sum_{i<j}\left\langle\eta_{i}, \eta_{j}\right\rangle^{2} .
\end{aligned}
$$

From this equation, it is obvious that the error depends both on the significant wave height $H_{s}$ and the correlation of the measurements taken at different locations. As stated earlier, each estimation of $H_{S}$ is based on about $N=30000$ measurements taken inside a box of about $500 \mathrm{~m} \times 65 \mathrm{~m}$ size. The first term $\left(H_{S}{ }^{4} / 128 N\right)$ in $(5)$ can be neglected in this configuration. For the second term, the root-mean-squared distance of point pairs appearing in the sum is of interest. Concentrating on the distance $l=500 \mathrm{~m}$ in flight direction, this results in

$$
\begin{aligned}
\operatorname{rms}(\text { distance }) & \approx\left(\frac{1}{l^{2}} \int_{0}^{l} \int_{0}^{l}(x-y)^{2} d x d y\right)^{1 / 2} \\
& \approx 200 \mathrm{~m} .
\end{aligned}
$$

Making some simplifying assumptions about the decorrelation properties of waves [24], a correlation magnitude of about $|c|=0.05$ for a typical sea state (100-m wavelength and 2-m wave height) and points $200 \mathrm{~m}$ apart is found. Equation (5) then simplifies

$$
\operatorname{stdv}(\zeta) \approx|c| \frac{H_{s}^{2}}{\sqrt{128}}
$$

As an example, this would give $\operatorname{stdv}(\zeta) \approx 0.018 \mathrm{~m}^{2}$ for $H_{s}=2 \mathrm{~m}$, which finally results in a relative error of the variance estimate of about $15 \%$. This is a reasonable accuracy for practical applications compared with the modeled data.

Another peculiarity of airborne scanning is the relative velocity between the wave propagation and the carrier of the 
TABLE II

Data Set SWh Overview Table Arranged According to the Flight Numbers Used in the Pangaea Data Set [29] and Flight Date.

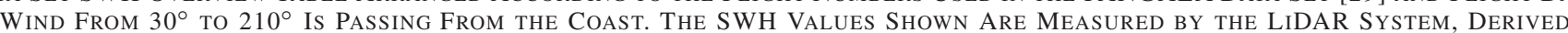
From the WAM Model InTERPolated In POSITION AND Time DuRing LiDAR MEASUREMENTS AND BuOY SWH MEASUREMENTS. F1 Denotes the Measurement at the FINO (ForschungsplattFormen IN NORD- Und OstSEe) PlatForm FINO1 IN THE Lower Middle of the German Bight, F3 the Measurement at FinO3 Close to the “Westerland” Buoy, EL the "ELBE" BuOY, AND HE the BuOY "Helgoland-NorD"

\begin{tabular}{|c|c|c|c|c|c|c|c|c|c|}
\hline \multicolumn{2}{|l|}{ Flight } & \multicolumn{2}{|c|}{ Windspeed and -direction } & \multicolumn{6}{|c|}{ Median SWH during measurements [cm] } \\
\hline $\mathbf{N}^{\circ}$ & Date & $\mathrm{FF}[\mathrm{m} / \mathrm{s}]$ & DD [deg] & LiDAR & WAM & F1 & F3 & EL & $\mathrm{HE}$ \\
\hline 1 & 20160906 & 7 & 210 & 62 & N/A & 49 & 75 & N/A & N/A \\
\hline 2 & 20160907 & 4 & 190 & 47 & N/A & 44 & 67 & $\mathrm{~N} / \mathrm{A}$ & N/A \\
\hline 3 & 20160907 & 4 & 190 & 44 & N/A & 38 & 69 & $\mathrm{~N} / \mathrm{A}$ & N/A \\
\hline 4 & 20160908 & 8 & 120 & 70 & N/A & 59 & 71 & N/A & N/A \\
\hline 5 & 20160909 & 6 & 240 & 56 & N/A & 56 & 67 & $\mathrm{~N} / \mathrm{A}$ & N/A \\
\hline 6 & 20160909 & 6 & 250 & 57 & N/A & 64 & 71 & N/A & N/A \\
\hline 7 & 20160910 & 7 & 190 & 97 & N/A & 82 & 126 & N/A & N/A \\
\hline 8 & 20160910 & 4 & 190 & 77 & N/A & 66 & 111 & N/A & N/A \\
\hline 9 & 20170330 & 15 & 240 & 87 & 128 & 98 & 116 & N/A & N/A \\
\hline 10 & 20170331 & 13 & 180 & 46 & 59 & 42 & 71 & N/A & N/A \\
\hline 11 & 20170405 & 14 & 310 & 142 & 166 & 156 & 270 & 118 & N/A \\
\hline 12 & 20170406 & 8 & 310 & 178 & 163 & 186 & 192 & 153 & N/A \\
\hline 13 & 20170409 & 7 & 220 & 50 & 53 & 48 & 78 & 38 & N/A \\
\hline 14 & 20170409 & 4 & 200 & 41 & 48 & 40 & 88 & 28 & N/A \\
\hline 15 & 20170411 & 8 & 300 & 205 & 181 & 203 & 235 & 176 & 166 \\
\hline 16 & 20170411 & 8 & 260 & 155 & 168 & 175 & 201 & 125 & 132 \\
\hline 17 & 20170413 & 16 & 290 & 229 & 223 & 244 & 234 & 198 & N/A \\
\hline 18 & 20170517 & 8 & 110 & 37 & 43 & 28 & 49 & 23 & N/A \\
\hline 19 & 20170517 & 12 & 120 & 38 & 51 & 45 & 40 & 23 & N/A \\
\hline 20 & 20170523 & 5 & 250 & 27 & 24 & 26 & 38 & 22 & N/A \\
\hline 21 & 20170523 & 11 & 310 & 76 & 55 & 84 & 73 & 38 & N/A \\
\hline 22 & 20170524 & 8 & 300 & 104 & 97 & 89 & 94 & 116 & N/A \\
\hline 23 & 20170524 & 9 & 270 & 79 & 77 & 69 & 81 & 92 & N/A \\
\hline 24 & 20170527 & 10 & 150 & 41 & 49 & 39 & 41 & 26 & N/A \\
\hline 25 & 20170527 & 12 & 140 & 40 & 58 & 43 & 47 & 23 & N/A \\
\hline 26 & 20170531 & 8 & 290 & 114 & 115 & 104 & 217 & 121 & N/A \\
\hline 27 & 20170531 & 9 & 290 & 141 & 136 & 134 & 254 & 145 & N/A \\
\hline 28 & 20170601 & 6 & 300 & 126 & N/A & 120 & 164 & N/A & N/A \\
\hline 29 & 20170602 & 4 & 170 & 44 & N/A & 47 & 57 & N/A & N/A \\
\hline 30 & 20170808 & 9 & 80 & 78 & 74 & 88 & 71 & N/A & N/A \\
\hline 31 & 20170808 & 14 & 80 & 75 & 70 & 100 & 65 & N/A & N/A \\
\hline 32 & 20170809 & 15 & 210 & 188 & 200 & 141 & 166 & N/A & N/A \\
\hline 33 & 20170809 & 13 & 240 & 149 & 177 & 110 & 173 & N/A & N/A \\
\hline 34 & 20170810 & 5 & 330 & 130 & 114 & 149 & 164 & N/A & N/A \\
\hline 35 & 20170814 & 8 & 150 & 90 & 84 & 87 & 101 & 26 & 55 \\
\hline 36 & 20170814 & 7 & 120 & 78 & 95 & 98 & 119 & 26 & 38 \\
\hline 37 & 20170815 & 8 & 180 & 63 & 77 & 74 & 81 & 26 & N/A \\
\hline 38 & 20170817 & 12 & 160 & 93 & 96 & 74 & 124 & 65 & N/A \\
\hline 39 & 20171014 & 15 & 260 & N/A & N/A & N/A & N/A & N/A & N/A \\
\hline 40 & 20171015 & 14 & 200 & N/A & N/A & N/A & N/A & N/A & N/A \\
\hline 41 & 20171015 & 13 & 190 & N/A & N/A & N/A & N/A & N/A & N/A \\
\hline
\end{tabular}

sensor. Therefore, Taylor's hypothesis of "frozen patterns" cannot be applied. For the first raw and second central moment that is used to estimate $H_{s}$, this effect, called "scanning distortion," has no influence since spatial locations of the measurements in the longitudinal and lateral directions have no influence on elevation variance.

\section{DATA FOR INTERCOMPARISONS}

Data sources for this study include satellite altimeter observations using data from the Sentinel-3 mission [25], [26] and buoy measurements at Heligoland ("Helgoland-Nord"), Scharhörn ("Elbe"), and Sylt ("Westerland") [10], [12], [27], outputs of model runs from the third-generation WAM model [28], and airborne LiDAR data obtained during WIPAFF [21], [29]. Fig. 1 shows all flight trajectories with running LiDAR data acquisition and the locations of the buoy measurements.

A tabular overview of all flights is presented in Table II. Besides wind parameters, SWH values from different sources are included to give a general impression on the wind-wave situation on every flight. Therefore, time series of 
SWH measurements are represented through its median values during the flight.

\section{A. In Situ Measurements}

The sea surface is measured by directional waverider buoys (Datawell, The Netherlands) [12], and the processed data are available every $30 \mathrm{~min}$. Processed buoy data ("HelgolandNord," "Elbe," and "Westerland," data provided by the Federal Maritime and Hydrographic Agency in Germany, and the "Landesbetrieb für Küstenschutz, Nationalpark und Meeresschutz Schleswig-Holstein") include the measurements of the wave height, propagation, and spectral properties. In addition, time series of the heave was available to process SWH for different time spans.

During the project WIPAFF, the airborne LiDAR measurements were not systematically coordinated with these measurements. However, additional overpasses of buoys were performed during measurement flights in 2020 to confirm the agreement of both measurement techniques.

\section{B. Satellite Observations}

This study considers the operational altimetry satellite Sentinel-3A [25], [26], [30], [31]. Satellite altimetry is based on radar technique that measures the ocean surface height with a precision of few centimeters. The observations use the Ku-band and provide high-quality sea state and wind speed estimations.

Sentinel-3A orbits similar to ENVISAT at an altitude of $814.5 \mathrm{~km}$. It is a sun-synchronous orbit and has a repeat cycle of 27 days. This explains why only a few colocations can be found, and the data for LiDAR and satellite intercomparisons are rare. The satellite is expected to provide an improvement of wave height measurements near the coast. Satellite measurements were bias corrected using a calibration relative to buoys [32]; therefore, a comparison of absolute levels between the buoy and satellite data cannot be conducted.

The satellite data used for the study are composed of along-track samplings [33], [34]. The along-track spatial resolution of Sentinel-3A can reach $300 \mathrm{~m}$ depending on the radar mode. A track close to the wind parks, where the LiDAR measurements are taken, is chosen for comparison.

\section{WAM Model Data}

Model data are available from the third-generation ocean wave model WAM [28]. This model solves the action balance equation, which describes the following:

1) wave generation by the wind;

2) wave dissipation by white capping and bottom friction;

3) four-wave interaction;

4) propagation of waves in variable bathymetry.

A 1-km model for the German Bight was nested into a 5-km North Sea model. The used model setup is part of the Coastal Observing System for Northern and Arctic Seas (COSYNA) run at the Helmholtz-Zentrum Geesthacht (HZG) [35], [36]. The required wind fields were taken from the operational atmospheric model runs of the German Weather Service (DWD). The model computes 2-D wave spectra with
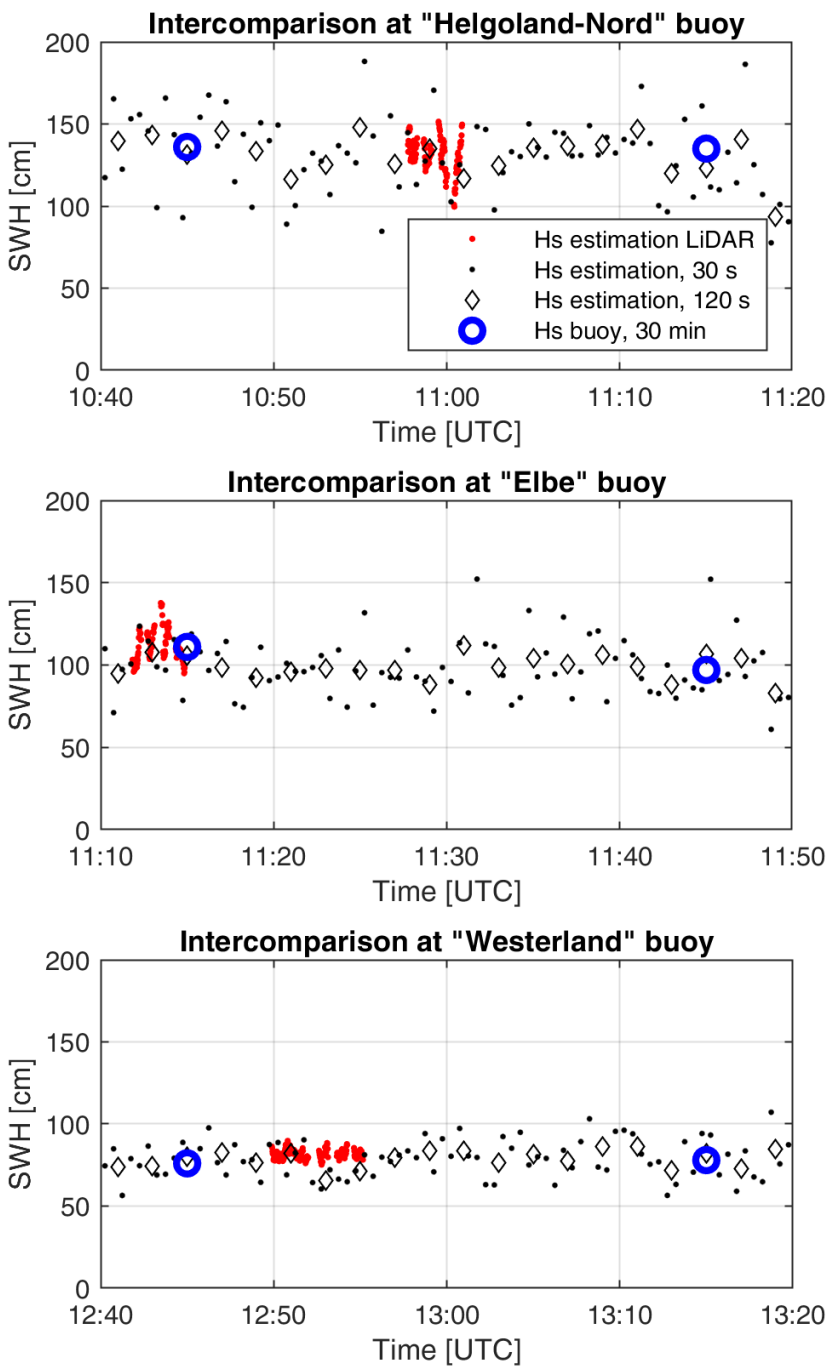

Fig. 3. Time series of retrieved SWH from LiDAR and buoy measurements at three different locations on May 5, 2020. Red dots show the SWH estimation from LiDAR measurements (time span of $10 \mathrm{~s}$ ), black dots indicate SWH estimations using buoy heave time series (time span $30 \mathrm{~s}$ ), diamond marks indicate the SWH estimations of buoy time series during a time span of $2 \mathrm{~min}$, and the blue circles denote calculated SWH over $30 \mathrm{~min}$. Data are plotted for the middle of the estimation time span.

30 directional $15^{\circ}$ sectors and 30 frequencies logarithmically spaced from 0.042 to $0.66 \mathrm{~Hz}$. In the used preoperational run, a set of integral wave parameters, such as significant wave height, peak period, or peak direction, is stored for each grid point. These variables are instantaneous outputs and are saved for every $3 \mathrm{~h}$.

The ocean wave model is affected by different types of systematic and stochastic errors. A lot of efforts were invested into the reduction of biases, e.g., associated with the parameterization of dissipation processes. It is well known that the remaining random errors are to a large extent due to the driving wind fields. Nevertheless, typical rms differences of model significant wave height with respect to buoy measurements are of the order of $0.3 \mathrm{~m}$ [37]. One has to take into account, however that these differences include significant errors contributed by the in situ measurements. This means that the actual model error can often be significantly lower than $0.3 \mathrm{~m}$ [38]. 


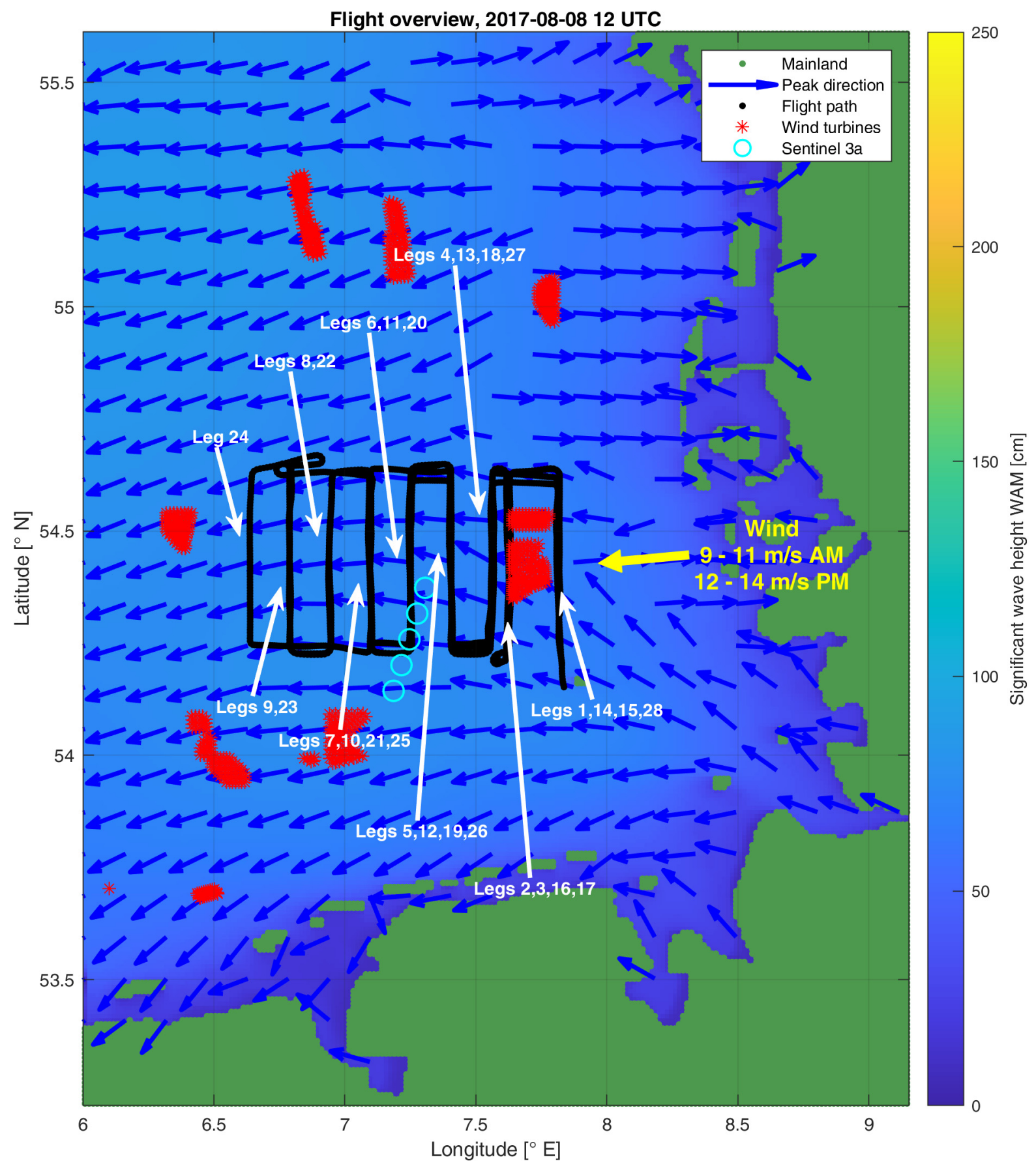

Fig. 4. WAM simulations showing the distribution of significant wave height (color-coded) on August 8, 2017, 12 UTC. Indicated in black is the flight path, and subsequent flight legs are enumerated in white. The peak wave direction is shown by the blue arrows. Individual wind turbines are given as red asterisks. The wind direction is indicated as yellow arrow. Sampling locations for the direct overpass of Sentinel-3A are marked as cyan circles.

\section{RESULTS}

In the first section, LiDAR data are evaluated by a direct intercomparison with buoy data. Subsequently, a brief case study allows to zoom into detailed features with a dedicated intercomparison between LiDAR, satellite, and WAM data.

\section{A. Evaluation of Airborne LiDAR Measurements Using Buoy Data}

During the Project X-Wakes, the follow-up project of WIPAFF, the opportunity was taken to fly rectangular patterns close to wave buoys in 2020. The SWH estimated by the LiDAR during these fly-bys can, therefore, directly be compared with in situ data.

Fig. 3 shows these intercomparisons at three different locations ("Helgoland-Nord," "Elbe," and "Westerland" locations marked in Fig. 1) on May 5, 2020. Despite the spatial distance of up to $5 \mathrm{~km}$ between the measured LiDAR surface and the buoy positions, a deviation similar to the error estimated in [see 5] is observed, depending strongly on the estimation time span of buoy data. Since the scatter of SWH in time is an inherent feature of the sea surface, differences in the scatter 
(a)

Significant Waveheight, 2017-08-08 AM

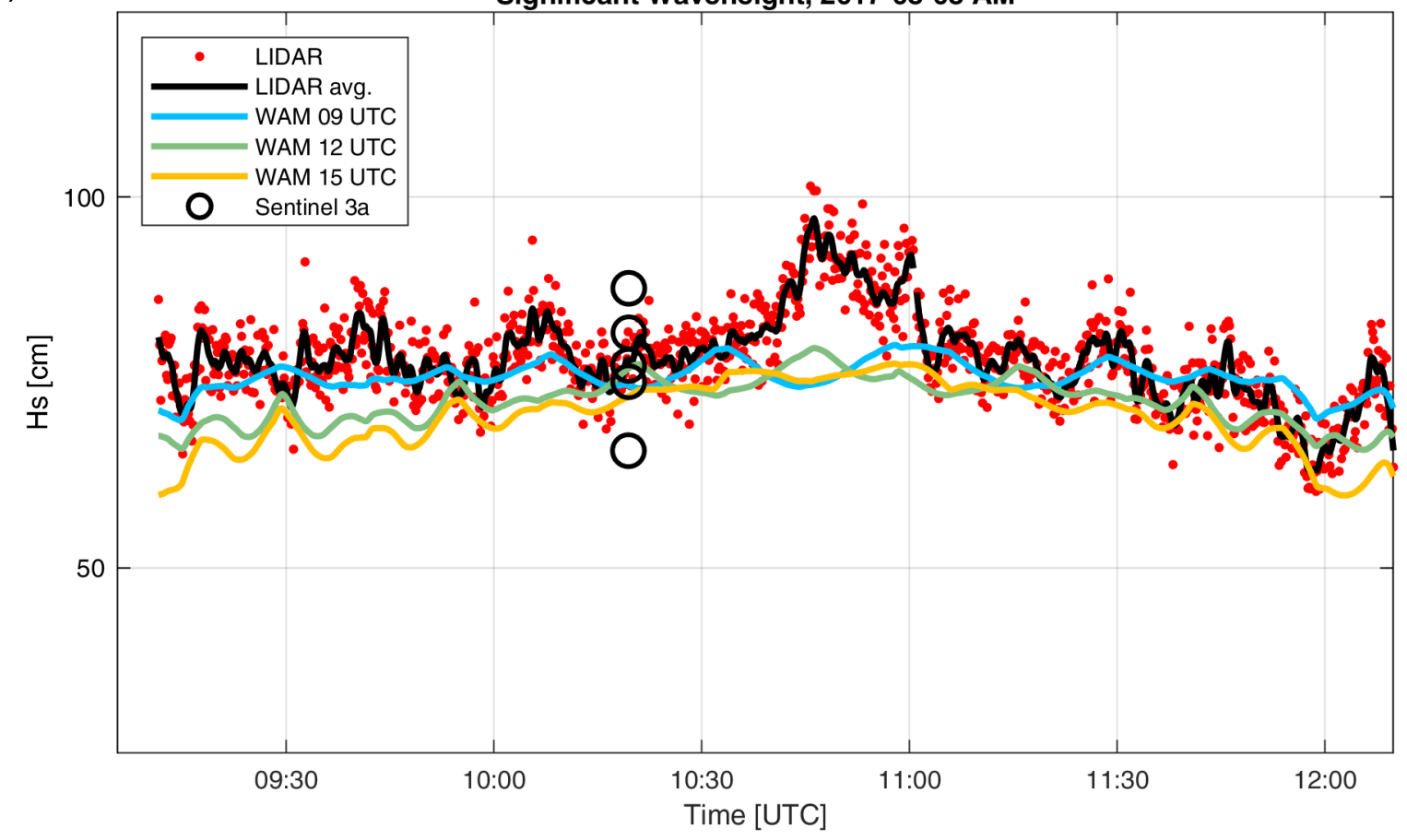

(b)

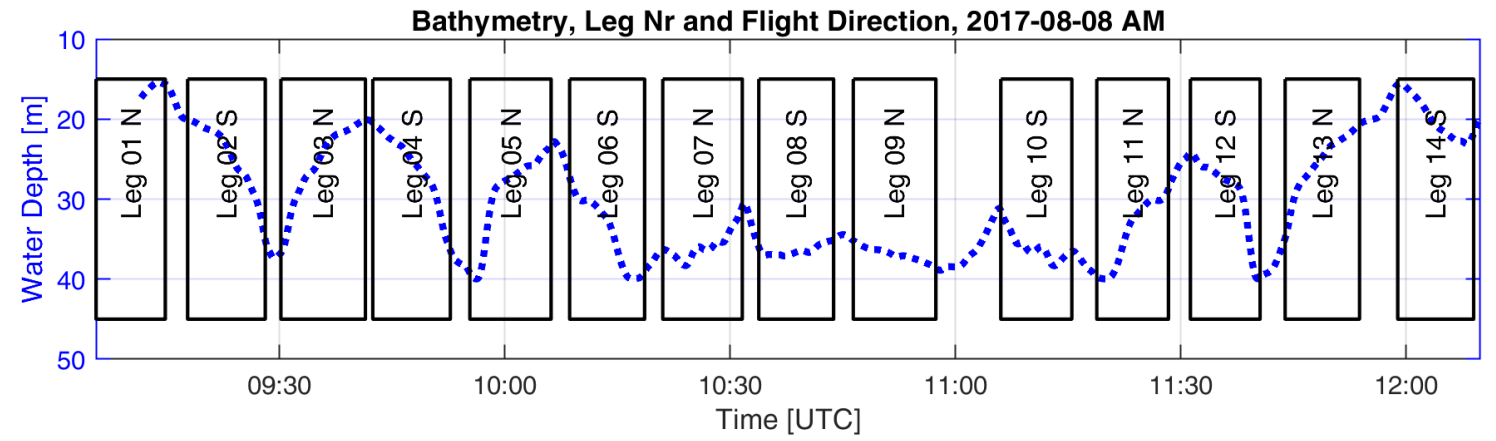

Fig. 5. Comparison of WAM and LiDAR Data on August 8, 2017, in the morning. In (a) significant wave heights are plotted over time where red dots are $\mathrm{H}_{s}$ estimations out of LiDAR measurements during $10 \mathrm{~s}$, the red line is the moving average over ten LiDAR $\mathrm{H}_{s}$ estimations, and the other colored lines are WAM outputs out of model runs for different times, interpolated on flight trajectory. Data from the satellite overpass come as black circles. In (b), overflown bathymetry is shown over time, and leg numbers, including its trajectory directions, are named inside boxes over leg time spans. The satellite overpass happened during measurements on the end of Leg 06 .

of SWH estimations depending on the estimation time span can be seen in the figure. Increasing the estimation time span would reduce the scatter but consequently decrease the temporal (buoy measurements) or spatial (LiDAR measurements) resolution.

\section{B. Case Study in a Growing Sea Situation}

The case study represents a situation where new ocean waves are created by wind from land to the sea and where small-scale variations in the wind field can have a significant impact on the wave growth and the spatial distribution of wave energy.

On August 8, 2017, the synoptic situation in the German Bight was dominated by a low-pressure system centered above The Netherlands/Western Germany. This involved flow from the east (wind direction: $80^{\circ}$ ) above the German Bight with a wind speed of around $9 \mathrm{~ms}^{-1}$ at hub height similar to the wind speed of the first case described earlier. During the day, the wind speed increased and reached $15 \mathrm{~ms}^{-1}$ in the afternoon. The air masses warmed up above land had temperatures exceeding the sea surface temperature of $18{ }^{\circ} \mathrm{C}$. This temperature inversion includes a stable atmospheric stratification. This is in agreement with a wake length exceeding $35 \mathrm{~km}$ [13].

Fig. 4 shows the data situation on August 8, 2017, around 10:19 UTC for the subsequent intercomparisons in a map of the German Bight, including a direct satellite overpass of the Sentinel-3A platform.

One can see wave peak direction from the WAM model pointing in easterly direction as well as wave peak direction arrows pointing in westerly direction. This is caused by 
(a)

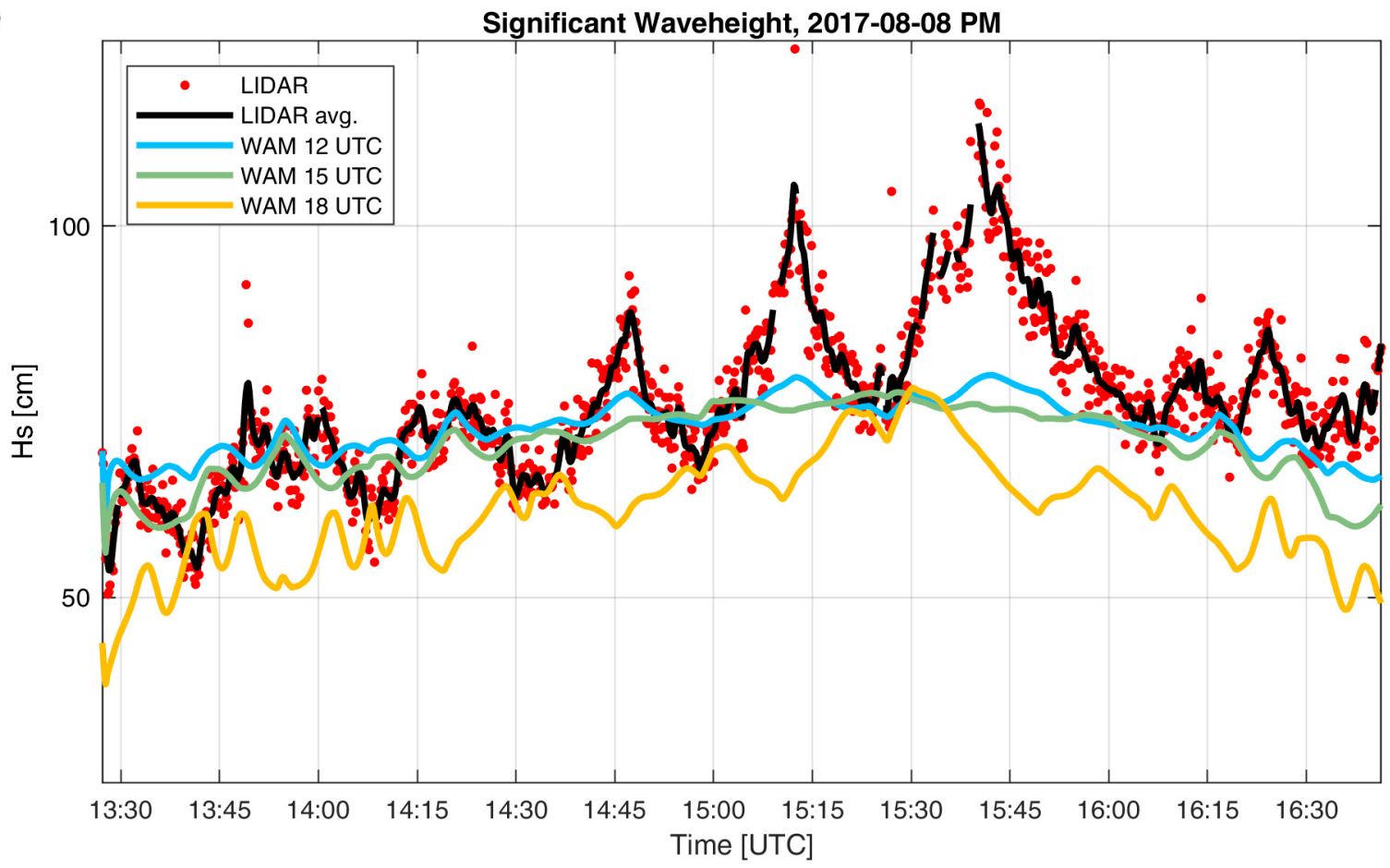

(b)

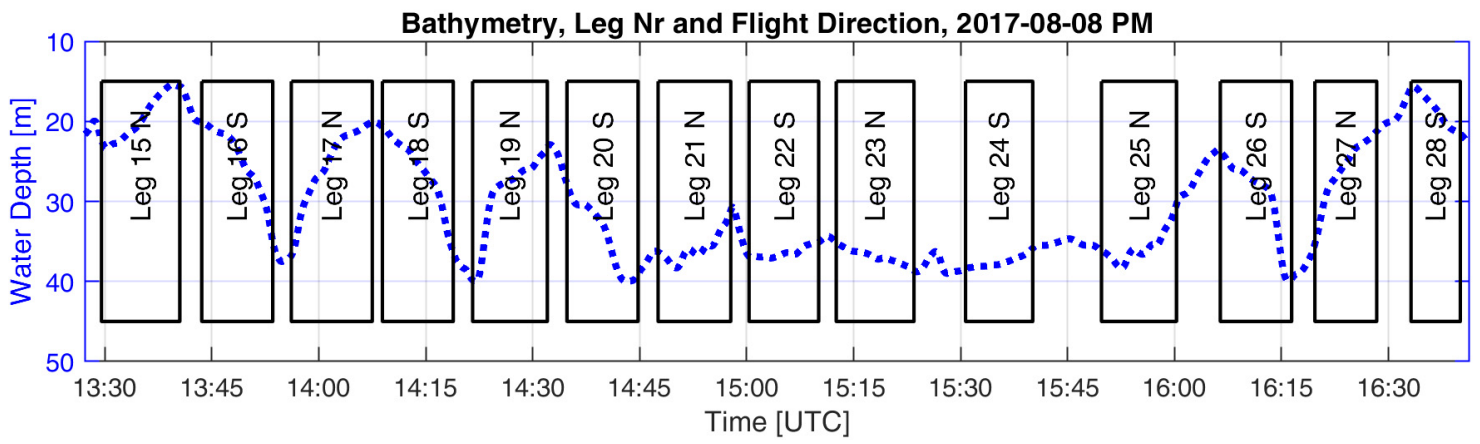

Fig. 6. Comparison of WAM and LiDAR Data on August 8, 2017, in the afternoon. In (a), significant wave heights are plotted over time where red dots are $\mathrm{H}_{s}$ estimations out of LiDAR measurements during $10 \mathrm{~s}$, the red line is the moving average over $10 \mathrm{LiDAR} \mathrm{H}_{s}$ estimations, and the other colored lines are WAM outputs out of model runs for different times, interpolated on flight trajectory. In (b), overflown bathymetry is shown over time, and leg numbers, including its trajectory directions, are named inside boxes over leg time spans.

the data set used, where peak direction is not separately treated for swell and for wind seas. Close to the land in easterly direction, peak directions indicate an underlying swell, whereas, in open seas, wind forcing dominates, and the wind direction coincides with wave peak direction. This indicates a complex ocean wave situation. On August 8, 2017, two flights were performed: one in the morning (08:35-12:33 UTC) and another in the afternoon (13:06-17:07 UTC).

Measurements on August 8, 2017, took place during the whole day in the German Bight. This allows to intensely compare WAM outputs during a complex wind/weather situation. Fourteen legs were flown in the morning (see Fig. 5), and a similar pattern was repeated in the afternoon (see Fig. 6). In the morning, the wind speed was around $9 \mathrm{~m} / \mathrm{s}$, the wind direction was east, and fetch was limited to a few tens of $\mathrm{km}$. Therefore, wave height was significantly less with $75 \mathrm{~cm}$ compared with the case study on April 11, 2017. On an hourly timescale, WAM outputs and measurements agree, but significant peaks in $\mathrm{H}_{s}$ appear around the legs 8, 9 [see Fig. 5(a)], and 20-25 [see Fig. 6(a)]. Generally, the airborne measured wave heights are up to $40 \mathrm{~cm}$ higher than the modeled wave heights. The underestimation of wave height by the model seems to be a local effect since regions close to the coast are not affected by such high deviations. A clear correlation between the bathymetry and the wave height as one might have expected is not observed for all legs [see Figs. 5 and 6(a) and (b)]. Assuming correct bathymetry data for the WAM model runs, the significant deviations between the measurements and model data in the southern parts of legs 8,9 , and 20-25 could be affected by atmospheric input since deviation peaks increase in time, correlating with the increasing wind speed in the afternoon from 12 to $14 \mathrm{~ms}^{-1}$. 
Satellite measurements agree $\pm 12 \mathrm{~cm}$ compared with the LiDAR measurements and depend strongly on the latitude of the measurement footprints.

In the afternoon, a wake with $55-\mathrm{km}$ length was observed using aircraft wind measurements. In addition, LiDAR measurement shows wake-induced variations in reflection, but SWH retrieved by the airborne LiDAR, as shown in II-B, seems not to be affected by the wake.

\section{CONCLUSION AND Discussion}

An airborne LiDAR was used to measure ocean waves in the German Bight. SWH varied between 0.4 and $2.3 \mathrm{~m}$, and data are validated against buoy measurements during direct overpasses, which confirms the error estimation conducted. Besides, a case is presented, which represents a wave growth dominated situation. Overall, the LiDAR in situ measurements are in very good agreement below 15\% deviation with the outputs of the third-generation numerical WAM model and within the expected error range of the wave model [36]. Therefore, airborne LiDAR may serve to calibrate satellite offsets in coastal areas, refine parameterization of WAM models, and study small-scale variations in complex areas (mostly shallow water). Estimation time span shows to have a strong influence to the scatter in retrieved SWH and, therefore, is an important tuning parameter for different applications.

Small-scale wave height variations not captured by the WAM model were observed by the airborne LiDAR, which seems to be connected to small-scale variations of the bathymetry and the driving wind field. The new observations, therefore, have a big potential for the optimization of coastal wave models that are still affected by a number of uncertainties regarding the bathymetry, the meteorological forcing, and the details of the wave growth and wave dissipation processes [36]. The error prediction is confirmed, in particular increased variations in $\mathrm{H}_{s}$ estimations in a rough sea state compared with a moderate sea state. The case study on April 11, 2017, has a visibly broader distribution of SWH derived from LiDAR measurements than the distribution of the measurements on August 8, 2017.

The promising results presented in this study motivate further analyses that can be carried out with the LiDAR data. Significant wave height is a parameter of importance for coastal and offshore engineering applications. WAM modeling is used to cover larger areas of the dimensions of the German Bight. The presented observations constitute a valuable tool to validate WAM simulations and to improve physical parameterizations as well as boundary conditions and forcing fields. Furthermore, sea surface parameters strongly interact with the atmosphere; therefore, the high-resolution data set can be used for coupled studies of atmosphere and North Sea, where the combination with simultaneous measurements of meteorological parameters will be further exploited.

\section{ACKNOWLEDGMENT}

The authors would like to thank the Aircraft Team H. Schulz, M. Bitter, T. Rausch, R. Hankers and T. Feuerle and the whole WIPAFF Project Team S. Emeis (KIT GarmischPartenkirchen), J. Bange (EKUT Tübingen), A. Platis (EKUT
Tübingen), S. K. Siedersleben (KIT Garmisch-Partenkirchen), B. Cañadillas (DEWI Wilhelmshaven), R. Foreman (DEWI Wilhelmshaven), and T. Neumann (DEWI Wilhelmshaven) for the support during the measurement campaigns. They would like to thank the Federal Maritime and Hydrographic Agency in Germany and the "Landesbetrieb für Küstenschutz, Nationalpark und Meeresschutz Schleswig-Holstein" for providing buoy data. They would also like to thank K. Herklotz, M. Wilms, and C. Senet for giving access to the data.

\section{REFERENCES}

[1] D. Atlas et al., "Problems and future directions in remote sensing of the oceans and troposphere: A workshop report," J. Geophys. Res. Oceans, vol. 91, no. C2, pp. 2525-2548, Feb. 1986. [Online]. Available: http://onlinelibrary.wiley.com/doi/10.1029/JC091iC02p02525/abstract

[2] J. Staneva, V. Alari, Ø. Breivik, J.-R. Bidlot, and K. Mogensen, "Effects of wave-induced forcing on a circulation model of the North Sea," Ocean Dyn., vol. 67, no. 1, pp. 81-101, Jan. 2017.

[3] E. V. Stanev, M. Dobrynin, A. Pleskachevsky, S. Grayek, and H. Günther, "Bed shear stress in the Southern North Sea as an important driver for suspended sediment dynamics," Ocean Dyn., vol. 59, no. 2, pp. 183-194, Apr. 2009.

[4] I. R. Young, Wind Generated Ocean Waves (Elsevier Ocean Engineering Book Series), no. 2, 1st ed. Amsterdam, The Netherlands: Elsevier, 1999.

[5] J. Staneva, K. Wahle, H. Günther, and E. V. Stanev, "Coupling of wave and circulation models in coastal-ocean predicting systems: A case study for the German Bight," Ocean Sci. Discuss., vol. 12, pp. 169-3197, May 2015.

[6] W. J. Pierson and L. Moskowitz, "A proposed spectral form for fully developed wind seas based on the similarity theory of S. A. Kitaigorodskii," J. Geophys. Res., vol. 69, no. 24, pp. 5181-5190, Dec. 1964. [Online]. Available: http://onlinelibrary.wiley.com/doi/10. 1029/JZ069i024p05181/abstract

[7] A. W. Bjerkaas and F. W. Riedel, "Proposed model for the elevation spectrum of a wind-roughened sea surface," Johns Hopkins Univ. Laurel Md Appl. Phys. Lab., Laurel, MD, USA, Tech. Rep. JHU/APL TG 1328, Dec. 1979. [Online]. Available: http://www.dtic.mil/docs/citations/ADA083426

[8] T. Elfouhaily, B. Chapron, K. Katsaros, and D. Vandemark, "A unified directional spectrum for long and short wind-driven waves," J. Geophys. Res., Oceans, vol. 102, no. C7, pp. 15781-15796, Jul. 1997. [Online]. Available: http://onlinelibrary.wiley.com/doi/ 10.1029/97JC00467/abstract

[9] P. A. Hwang, "A note on the ocean surface roughness spectrum*," J. Atmos. Ocean. Technol., vol. 28, no. 3, pp. 436-443, Mar. 2011.

[10] O. Roggenbuck, J. Reinking, and T. Lambertus, "Determination of significant wave heights using damping coefficients of attenuated GNSS SNR data from static and kinematic observations," Remote Sens., vol. 11, no. 4, p. 409, Feb. 2019. [Online]. Available: https://www.mdpi.com/2072-4292/11/4/409

[11] F. Ardhuin et al., "Semiempirical dissipation source functions for ocean waves. Part I: Definition, calibration, and validation," J. Phys. Oceanogr., vol. 40, no. 9, pp. 1917-1941, Sep. 2010.

[12] K. Herklotz, "Oceanographic results of two years operation of the first offshore wind research platform in the German Bight-FINO1," DEWI Magazin, vol. 30, pp. 47-51, Feb. 2007. [Online]. Available: http://www.dewi.de/dewi/fileadmin/pdf/publications/Magazin_30/09.pdf

[13] A. Platis et al., "First in situ evidence of wakes in the far field behind offshore wind farms," Sci. Rep., vol. 8, no. 1, Feb. 2018, Art. no. 2163. [Online]. Available: https://www.nature.com/articles/s41598-01820389-y

[14] S. Emeis et al., "Exploring the wakes of large offshore wind farms," J. Phys., Conf. Ser., vol. 753, Sep. 2016, Art. no. 092014. [Online]. Available: https://iopscience.iop.org/article/10.1088/1742-6596/753/9/ 092014

[15] G. T. Csanady, Air-Sea Interaction: Laws and Mechanisms. Cambridge, U.K.: Cambridge Univ. Press, Mar. 2001.

[16] J. Vrbancich, W. Lieff, and J. Hacker, "Demonstration of two portable scanning LiDAR systems flown at low-altitude for investigating coastal sea surface topography," Remote Sens., vol. 3, no. 9, pp. 1983-2001, Sep. 2011. [Online]. Available: http://www.mdpi.com/2072-4292/3/9/ 1983 
[17] B. D. Reineman, L. Lenain, D. Castel, and W. K. Melville, "A portable airborne scanning LiDAR system for ocean and coastal applications," J. Atmos. Ocean. Technol., vol. 26, no. 12, pp. 2626-2641, Dec. 2009. [Online]. Available: https://journals.ametsoc.org/doi/abs/ 10.1175/2009JTECHO703.1

[18] P. A. Hwang, W. B. Krabill, W. Wright, R. N. Swift, and E. J. Walsh, "Airborne scanning LiDAR measurement of ocean waves," Remote Sens. Environ., vol. 73, no. 2, pp. 236-246, Aug. 2000. [Online]. Available: http://www.sciencedirect.com/science/article/pii/S0034425700000985

[19] E. J. Walsh, D. W. Hancock, D. E. Hines, R. N. Swift, and J. F. Scott, "Directional wave spectra measured with the surface contour radar," J. Phys. Oceanogr, vol. 15, no. 5, pp. 566-592, May 1985. [Online]. Available: https://journals.ametsoc.org/jpo/article/15/5/566/7187/ Directional-Wave-Spectra-Measured-with-the-Surface

[20] U. Corsmeier, R. Hankers, and A. Wieser, "Airborne turbulence measurements in the lower troposphere onboard the research aircraft Dornier 128-6, D-IBUF," Meteorologische Zeitschrift, vol. 10, no. 4, pp. 315-329, Oct. 2001. [Online]. Available: http://www.schweizerbart. de/papers/metz/detail/10/49163/Airborne_turbulence_measurements_in_ the_lower_trop?1=DE

[21] A. Lampert et al., "In situ airborne measurements of atmospheric and sea surface parameters related to offshore wind parks in the German Bight," Earth Syst. Sci. Data, vol. 12, no. 2, pp. 935-946, Apr. 2020 [Online]. Available: https://essd.copernicus.org/articles/12/935/2020/

[22] L. H. Holthuijsen, Waves in Oceanic and Coastal Waters. Cambridge, U.K.: Cambridge Univ. Press, Jan. 2007, p. 404.

[23] K. Triantafyllopoulos, "On the central moments of the multidimensional Gaussian distribution," Math. Sci., vol. 28, no. 2, pp. 125-128, 2003.

[24] K. Hasselmann et al., "Measurements of wind-wave growth and swell decay during the Joint North Sea Wave Project (JONSWAP)," Deutsche Hydrographische Zeitschrift Ergänzungsheft, vol. 12, pp. 1-95, Jan. 1973.

[25] O. Montenbruck, S. Hackel, and A. Jäggi, "Precise orbit determination of the Sentinel-3A altimetry satellite using ambiguity-fixed GPS carrier phase observations," J. Geodesy, vol. 92, no. 7, pp. 711-726, Jul. 2018, doi: 10.1007/s00190-017-1090-2.

[26] Z. Malenovský et al., "Sentinels for science: Potential of Sentinel$1,-2$, and -3 missions for scientific observations of ocean, cryosphere, and land," Remote Sens. Environ., vol. 120, pp. 91-101, May 2012. [Online]. Available: http://www.sciencedirect.com/science/ article/pii/S0034425712000648

[27] A. Westerhellweg, B. Cañadillas, F. Kinder, and T. Neumann, "Wake Measurements at alpha ventus-Dependency on stability and turbulence intensity," J. Phys., Conf. Ser., vol. 555, Dec. 2014, Art. no. 012106, doi: $10.1088 / 1742-6596 / 555 / 1 / 012106$.

[28] G. J. Komen, L. Cavaleri, M. Donelan, K. Hasselmann, S. Hasselmann, and P. A. E. M. Janssen, Dynamics and Modelling of Ocean Waves. Cambridge, U.K.: Cambridge Univ. Press, Aug. 1996.

[29] K. Bärfuss et al., In-situ Airborne Measurements of Atmospheric and Sea Surface Parameters Related to Offshore Wind Parks in the German Bight. Pangaea, 2019, doi: 10.1594/PANGAEA.902845.

[30] R. Scharroo et al., "Jason continuity of services: Continuing the Jason altimeter data records as copernicus Sentinel-6," Ocean Sci., vol. 12, no. 2, pp. 471-479, Apr. 2016. [Online]. Available: http://www.oceansci.net/12/471/2016/os-12-471-2016.pdf

[31] W. Bannoura, F. Parisot, P. Vaze, and G. Zaouche, "Jason-3 project status," in Proc. Ocean Surf. Topogr. Sci. Team Meeting Presentations (OSTST), Venice, Italy, Sep. 2012. [Online]. Available: http://www.aviso.oceanobs.com/fileadmin/documents/OSTST/2012/oral/ 01_thursday_27/01_general/05_jason3_status_Couderc.pdf

[32] H. H. Sepulveda, P. Queffeulou, and F. Ardhuin, "Assessment of SARAL/AltiKa wave height measurements relative to buoy, Jason-2, and Cryosat-2 data," Mar. Geodesy, vol. 38, no. sup1, pp. 449-465, Sep. 2015

[33] P.-Y. Traon et al., "The copernicus marine environmental monitoring service: Main scientific achievements and future prospects," Mercator Ocean J., vol. 56, p. 100, Sep. 2017.

[34] A. Wiese, J. Staneva, J. Schulz-Stellenfleth, A. Behrens, L. Fenoglio-Marc, and J.-R. Bidlot, "Synergy of wind wave model simulations and satellite observations during extreme events," Ocean Sci., vol. 14, no. 6, pp. 1503-1521, Dec. 2018.

[35] E. Stanev, J. Schulz-Stellenfleth, J. Staneva, S. Grayek, J. Seemann, and W. Petersen, "Coastal observing and forecasting system for the German Bight. Estimates of hydrophysical states," Ocean Sci., vol. 7, pp. 1-15, Apr. 2011
[36] J. Staneva, A. Behrens, and N. Groll, "Recent advances in wave modelling for the North Sea and German Bight," Die Küste, vol. 81, pp. 233-254, Jan. 2014.

[37] J. Staneva, A. Behrens, and K. Wahle, "Wave modelling for the German Bight coastal-ocean predicting system," J. Phys., Conf. Ser., vol. 633, Sep. 2015, Art. no. 012117.

[38] J. Schulz-Stellenfleth and J. Staneva, "A multi-collocation method for coastal zone observations with applications to Sentinel-3A altimeter wave height data," Ocean Sci., vol. 15, no. 2, pp. 249-268, Mar. 2019.

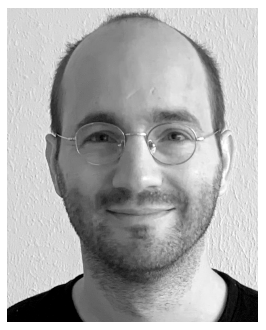

Konrad Bärfuss received the diploma degree in aeronautical and aerospace engineering from $\mathrm{TU}$ Braunschweig, Braunschweig, Germany.

$\mathrm{He}$ is with the Institute of Flight Guidance, Technische Universitat Carolo-Wilhelmina zu Braunschweig Carl-Friedrich-Gauss-Fakultat, Braunschweig, where he works on measurement techniques and airborne meteorology.

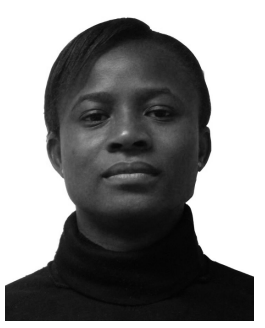

Bughsin Djath received the master's degree in physical oceanography from the University of Abomey-Calavi, Benin, and the Ph.D. degree in physical oceanography from the University of Grenoble Alpes, Grenoble, France, in 2014.

She was with the Laboratoire d'Etude en Géophysique et Océanographie Spatiale (LEGOS), France, on satellite altimetry and numerical modeling. She has been with the Institute of Coastal Research, Helmholtz-Zentrum Geesthacht, Geesthacht, Germany, since 2016. Her works are focused on the investigation of offshore wind park effects on the atmosphere and ocean through SAR data.

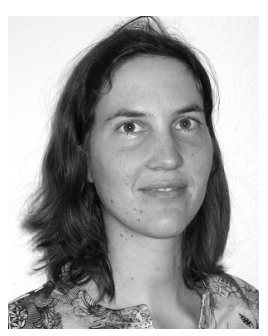

Astrid Lampert received the diploma degree in physics from Ludwid-Maximilians-Universität Munich, Munich, Germany, and the Ph.D. degree from the University of Potsdam, Germany, in 2010.

Since then, she works with TU Braunschweig, Braunschweig, Germany, in the field of airborne meteorology and measurement techniques.

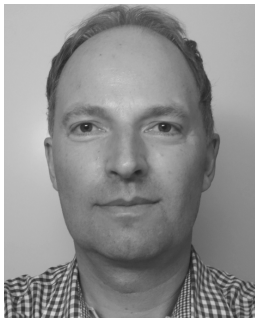

Johannes Schulz-Stellenfleth received the diploma degree in applied mathematics and the Ph.D. degree in estimation of 2-D wave spectra from complex SAR data from the University of Hamburg, in 1996 and 2003, respectively.

In 1996, he joined German Remote Sensing Data Center (DFD), Oberpfaffenhofen, Germany. In the framework of different national (FEME, SARPAK, TIDE, KORIOLIS) and European projects (MAXWAVE, COST 714, MERSEA) he worked on the derivation of ocean wave and wind parameters from synthetic aperture radar data. In 2008, he joined Model and Data Assessment (KSD) Department, Institute for Coastal Research, Helmholtz-Zentrum Geesthacht, Geesthacht, Germany. He works in ocean circulation modeling with a focus on assimilation. One of his main interests is the assimilation of HF radar data. He has worked on this issue in the framework of different European projects (MYOCEAN-2, JERICO, and FIELD_ac). 